\title{
Investigation on Double Wire Metal Inert Gas Welding of A7N01-T4 Aluminum Alloy in High-Speed Welding
}

https://doi.org/10.1515/htmp-2018-0073

Received April 25, 2018; accepted August 06, 2018

\begin{abstract}
Four-millimeter thick A7N01-T4 aluminum alloy plates were welded by double wire metal inert gas welding (DWMW) in high welding speeds, ranging from 1100 to $1250 \mathrm{~mm} / \mathrm{min}$. The results show that a sound joint could be obtained at a high speed of $1200 \mathrm{~mm} / \mathrm{min}$ using DWMW. The weld zone (WZ) in the joint showed a dendritic structure of equiaxed grains, and in the fusion zone (FZ), the microstructure existed as a fine equiaxed crystal structure about $100 \mu \mathrm{m}$ in thickness. In the WZ adjacent to the FZ, elongated columnar crystal structure distributed along to the interface, and coarse microstructure in the heat affected zone (HAZ) were found, showing a typical rolling texture. The main precipitates in the WZ were assumed to be Fe-enriched phases, and Mg- and Zn-enriched phases. Tensile fracture generally occurred in the $\mathrm{WZ}$ adjacent to the FZ with a decrease in ductility, and it was consistent with the results of the microstructure analysis and hardness profile. The mean ultimate tensile strength and elongation of specimens were 302 MPa and $4.5 \%$, respectively.
\end{abstract}

Keywords: double wire metal inert gas welding, aluminum alloys, high-speed welding

\section{Introduction}

$7 \mathrm{xxx}$ aluminum alloy is an Al-Zn-Mg-(Cu) alloy with good extrusion performance and high strength [1-4], and it has become the main alloy of large thin-walled, high-precision

*Corresponding author: Rongzheng $\mathrm{Xu}$, College of Material Science and Engineering, Shenyang Aerospace University, 37 Daoyi South Street Shenyang, 110136 China, E-mail: rzxu@imr.ac.cn

Zhicheng Wei: E-mail: verjus@foxmail.com, Hui Li:

E-mail: 1301005170@qq.com, Yanxi Hou:

E-mail: 1731204249@qq.com, Xuming Guo:

E-mail: 252741470@qq.com, College of Material Science and

Engineering, Shenyang Aerospace University, 37 Daoyi South Street

Shenyang, 110136 China solid and hollow profiles for aerospace and transportation vehicles $[3,5,6]$. At present, the fusion joining methods used in $7 \mathrm{xxx}$ aluminum alloy welding mainly include metal inert gas (MIG) welding, laser welding and laserarc hybrid welding [5, 7-13].

MIG welding process has the advantages of simple operation, low welding process cost, and good gap tolerance $[5,10]$. For MIG welding of $7 \mathrm{xxx}$ aluminum alloy, Yang et al. fabricated 4-mm A7N01 plates at a welding speed of about $420 \mathrm{~mm} / \mathrm{min}$ [14]. Similarly, Potluri et al. reported that $1.6 \mathrm{~mm} 7005$ plates were successfully joined together by pulsed-current MIG welding at 203 $\mathrm{mm} / \mathrm{min}$ [15]. Above investigations indicated clearly that MIG welding is not suitable for the requirement of high efficiency, and due to the low energy density, it imposes many problems such as burn through, large heat input, and distortion $[5,10,16]$. Laser welding, because of its concentration of energy density, high welding speed, high precision, low heat input, and flexibility, becomes a novel technical method for $7 \mathrm{xxx}$ alloy welding [9]. Detailed experiment and analysis were carried out by Katayama et al. on the effect of $\mathrm{CO}_{2}$ laser welding conditions on porosity formation during high-speed welding [8]. Also, a study of the feasibility of laser welding of AA7075-T6 showed that this method is highly susceptible to porosity [17], which indicates that the application of laser welding in practice still remains a technological challenge, due to its high reflectivity of aluminum to light, the keyhole instability, vaporization of zinc and/or magnesium, and high cost of equipment shortcomings [18]. Laser-hybrid welding, as a relatively new fusion welding method, has been considered to be a promising precision joining technique which has a high-energy utilization and welding speed [5]. $\mathrm{Hu}$ et al. successfully welded A7075 plates by laser-gas metal arc welding, achieving a full penetration at a travel speed of $6 \mathrm{~m} / \mathrm{min}$ [19]. However, a number of researchers have presented that due to the complicated operation and the demanding synergic effect between the two heat sources, its wide applications are limited [20-22]. According to above analyses, to expand its available applications, providing a low cost and high 
welding efficiency method to weld A7N01P has become a more pressing problem $[5,8,10]$.

Double wire MIG welding (DWMW) simultaneously provides heat energy to one molten pool, and it can directly perform welding process without preheating, change the heat distribution, improve the deposition rate, and effectively avoid various other relative disadvantages. As it can attain a higher welding productivity and ameliorate the welding formation in practice, DWMW has attracted extensive attention at present [23-28]. A lot of work has been reported that steel joints with a high performance could be obtained at a high welding speed by DWMW [23, 26-28], but the investigation of DWMW on aluminum alloys is scarce in the literature [24].

In this paper, DWMW using ER 5356 filler wire was applied to A7N01P welding, aiming to improve the welding efficiency at a low cost. In addition, the microstructure and mechanical properties of the weld joints were analyzed. Furthermore, the relation between welding speeds of aluminum alloy plates with different thicknesses and welding technologies was discussed in order to provide the guidance for the industrial applications of DWMW.

\section{Experimental}

The butt welding plates were obtained by a DWMW system (GLC503Quinto-Tandem, CLOOS, Germany) (Figure 1). The DWMW arcs were generated by direct-current torches, at an angle of $90^{\circ}$ to the workpiece. The power sources were operated with positive polarity on the wires. Shielding gas was argon with a purity of $99.99 \%$, flowed at $25 \mathrm{~L} / \mathrm{min}$. The distance between the gas nozzle and base metal (BM) was set as $16 \mathrm{~mm}$. The torches were kept

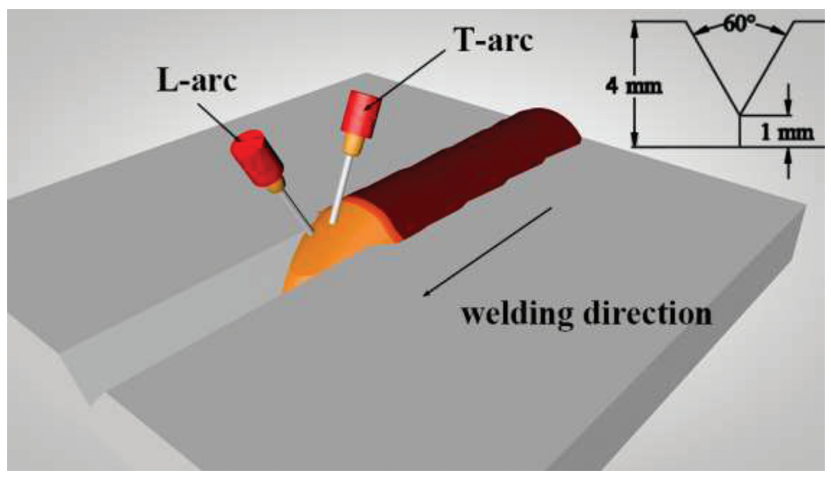

Figure 1: Schematic of DWMW process. at rest and the workpieces were moved with the moving stages. Welding was carried out by filling the weld groove (Figure 1) in a single pass.

A7N01-T4 aluminum alloy plates, $300 \mathrm{~mm} \times 150 \mathrm{~mm} \times$ $4.0 \mathrm{~mm}$ in dimension and extruded ER5356 aluminum alloy wire of $1.2 \mathrm{~mm}$ in diameter were used as the base workpieces and filler wire, respectively. Chemical compositions of the BM and filler wire are shown in Table 1, and microstructure of the BM is shown in Figure 2. The welding speeds were $1100 \mathrm{~mm} / \mathrm{min}, 1150 \mathrm{~mm} / \mathrm{min}, 1200$ $\mathrm{mm} / \mathrm{min}$ and $1250 \mathrm{~mm} / \mathrm{min}$, and the welding parameters of DWMW are shown in Table 2. The two welding torches were defined as the leading arc (L-arc) and the trailing arc (T-arc), respectively (Figure 1).

The testing specimens of weldments were stored at room temperature $(275 \mathrm{~K}$ ) for about 76 days so that they could achieve a sufficient degree of nature aging. For metallographic examination, specimens were sectioned through the center of the joints and parallel to the loading direction. After being mechanically ground and polished, the specimens were etched with Keller's reagent consisting of $2 \mathrm{~mL} \mathrm{HF}, 3 \mathrm{~mL} \mathrm{HCl}, 5 \mathrm{~mL} \mathrm{HNO}_{3}$ and $190 \mathrm{~mL} \mathrm{H}_{2} \mathrm{O}$. Microstructure was examined by optical microscope (OM) and LEO Supra 35 scanning electron microscope (SEM) with energy dispersive X-ray spectrometer (EDS).

Hardness profile across weld joint obtained at the welding speed of $1200 \mathrm{~mm} / \mathrm{min}$ was measured at half the weld thickness with a load of $100 \mathrm{~g}$ and a duration of $10 \mathrm{~s}$. Tensile tests were carried out at a constant speed of $1 \mathrm{~mm} / \mathrm{min}$ on a Zwick/Roell Z050 tester. Transverse oriented tensile specimens at $1200 \mathrm{~mm} / \mathrm{min}$ were machined, and Figure 3 illustrates the geometry and dimensions of the tested specimens. The weld zone (WZ) was at the center of the specimens, and welding reinforcements on the weld surface were eliminated before conducting the tests. The property values for each condition were calculated by averaging three test results. Additionally, analysis of the fracture location and morphology were performed using the OM and SEM.

\section{Results}

\section{High welding speed of A7N01 alloy}

Figures 4(a), 4(b) and 4(c) show the weld surfaces which were produced at the speeds of $1100 \mathrm{~mm} / \mathrm{min}$, $1150 \mathrm{~mm} / \mathrm{min}, 1200 \mathrm{~mm} / \mathrm{min}$, respectively. It could be 
Table 1: Chemical compositions of the BM and the welding wire (wt.\%).

\begin{tabular}{|c|c|c|c|c|c|c|c|c|c|}
\hline & Si & $\mathrm{Fe}$ & $\mathrm{Cu}$ & $M n$ & Mg & $\mathrm{Cr}$ & $\mathrm{Zn}$ & $\mathrm{Ti}$ & Al \\
\hline A7N01 & $\leq 0.3$ & $\leq 0.35$ & $\leq 0.2$ & $0.2-0.7$ & $0.1-2.0$ & $\leq 0.3$ & $4.0-5.0$ & $\leq 0.2$ & Bal. \\
\hline ER5356 & $\leq 0.25$ & $\leq 0.40$ & $\leq 0.1$ & $0.05-0.20$ & $4.5-5.5$ & $0.05-0.2$ & $\leq 0.1$ & $0.06-0.2$ & Bal. \\
\hline
\end{tabular}

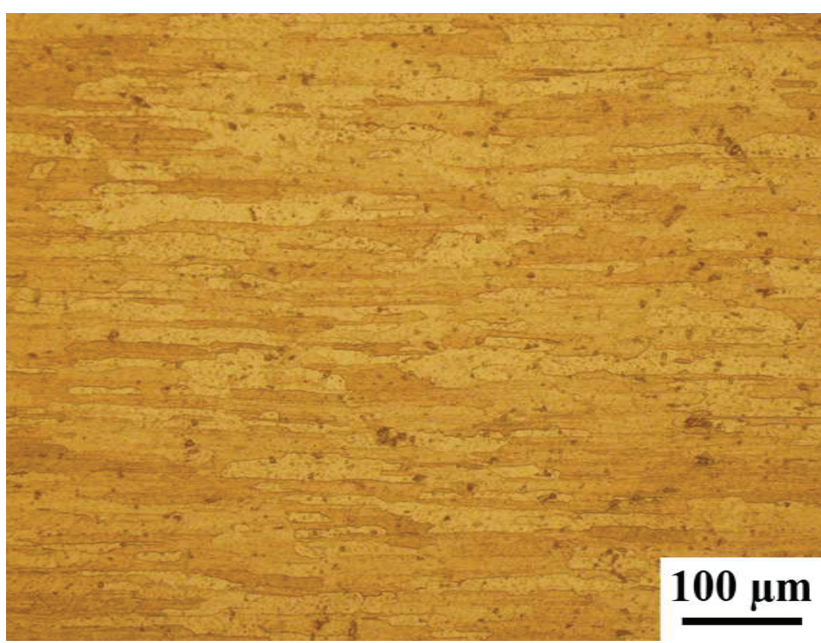

Figure 2: Micrographs of the BM A7N01-T4.

Table 2: Welding process settings and parameters.

\begin{tabular}{lrrr}
\hline & $\begin{array}{r}\text { Wire feed } \\
\text { rate }(\mathrm{m} / \mathrm{min})\end{array}$ & $\begin{array}{r}\text { Average } \\
\text { voltage }(\mathrm{V})\end{array}$ & $\begin{array}{r}\text { Average } \\
\text { current (A) }\end{array}$ \\
\hline Leading wire & 12.8 & 22.7 & 190 \\
Trailing wire & 10.8 & 23.8 & 162 \\
\hline
\end{tabular}

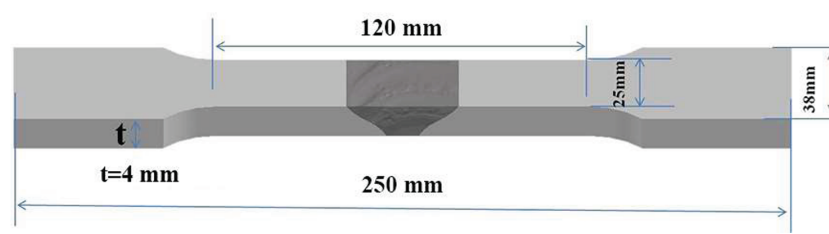

Figure 3: Dimensions of the sample for performance testing.

observed that the weld surfaces had acceptable visual finishes with satisfactory quality, and no distinct arc interruption occurred could be observed. However, increasing with the welding speed $(1250 \mathrm{~mm} / \mathrm{min})$, the welding bead became bad (Figure 4(d)). Therefore, according to the advantages of high speed and consistent quality, the DWMW joint obtained at $1200 \mathrm{~mm} / \mathrm{min}$ was selected for further analysis.
Figure 5 shows the typical cross-section photograph of a DWMW joint, furtherly exhibiting that the full penetration of $4 \mathrm{~mm}$ sheets could be successfully realized by DWMW at $1200 \mathrm{~mm} / \mathrm{min}$. The welding joint presented three different regions as follows: the WZ, the fusion zone (FZ) and the heat affected zone (HAZ). The macrograph shows a symmetry along the centerline of the weld. The effect of melting and mixing between the filler wire and BM resulted in some differences in microstructure and mechanical properties of each region.

\section{Microstructure of the joints}

Figure 6(a) shows the optical microstructure of the WZ in a DWMW joint. It could be clearly observed that, the central zone showed a dendritic structure of equiaxed grains, which dramatically altered the rolled microstructure of the BM (Figure 2), and had different grain orientations. The grain boundaries were large and the eutectic structure at the grain boundary was short and distributed heterogeneously (Figure 6(b)). The composition of the WZ was further investigated by SEM. The results show that some large precipitates distributed along grain boundaries. In addition, a few finely dispersed precipitates were also observed in this zone (Figures 7(a) and 7(b)). EDS analysis revealed that the large precipitate was consisted of $84.27 \mathrm{at} . \% \mathrm{Al}$, 8.64at.\% $\mathrm{Fe}$, 3.49at.\% Mg, 2.19at.\% Zn, and 1.42at.\% Mn (Figure 7 (c)), and was therefore assumed to be a-Al phases with Fe-enriched precipitates. The composition of small precipitates in the WZ adjacent to the FZ was further identified by EDS, and the results showed that contents of $\mathrm{Mg}$ and $\mathrm{Zn}$ elements of small precipitates were higher than that of a-Al phases (Figures 7(d), 7(e) and 7(f)), so they may be $\mathrm{Mg}$ - and $\mathrm{Zn}$-enriched precipitates.

The micrographs of the FZ, HAZ, fine equiaxed crystal zone and columnar crystals are clearly distinguished in Figure 6(c). In the FZ, the microstructure existed as a fine equiaxed crystal structure about $100 \mu \mathrm{m}$ in thickness (Figure 6(d)). In the WZ adjacent to the FZ, elongated columnar crystal structure distributed along to the 

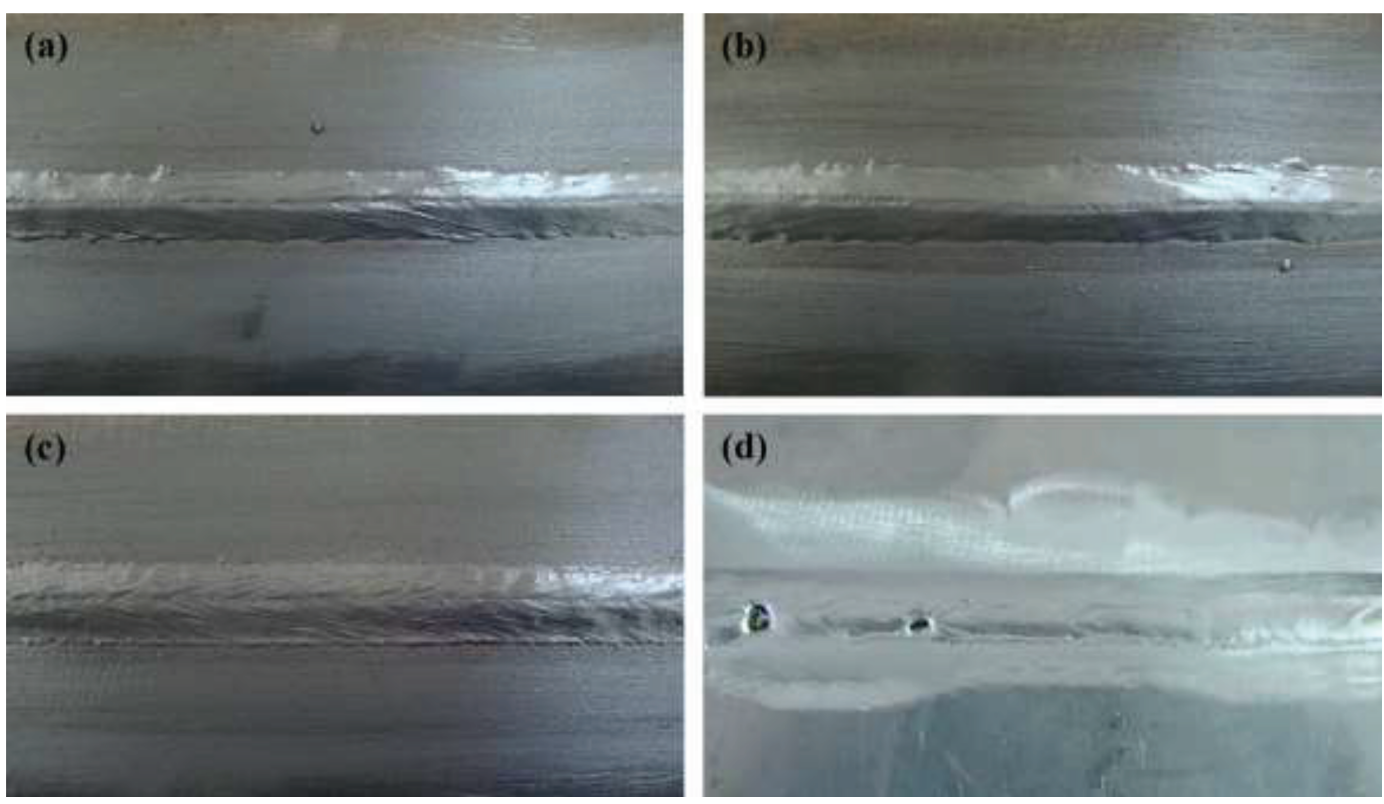

Figure 4: Appearances of butt weld seams under different welding speeds: (a) $1100 \mathrm{~mm} / \mathrm{min}$, (b) $1150 \mathrm{~mm} / \mathrm{min}$, (c) $1200 \mathrm{~mm} / \mathrm{min}$ and (d) $1250 \mathrm{~mm} / \mathrm{min}$.

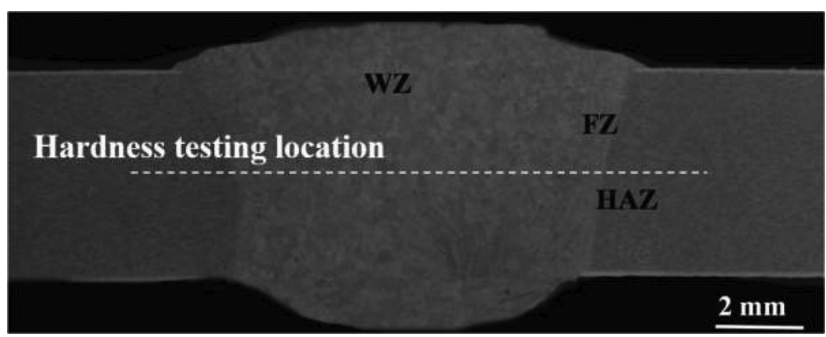

Figure 5: Cross-sectional overview of a DWMW A7N01P joint $(1200 \mathrm{~mm} / \mathrm{min})$.

interface. The columnar crystal structure toward the fusion center grew up around $300 \mu \mathrm{m}$ width along the FZ boundaries.

Coarse microstructure in the HAZ was found showing a typical rolling texture (Figure 6(c)). It was more clearly to identify as a predominantly discontinuous equiaxed dendritic structure in the HAZ produced by DWMW (Figure 6(d)). The grain size was larger than that in the BM. In the HAZ of the DWMW joint, there was a partially melted structure of about $150 \mu \mathrm{m}$ width. The region (Figure 6(d)) adjacent to the partially melted zone presented no evidence of excessive grain growth, dissolution or coarsening of second phase particles attributed to over-heating. The BM is characterized by a typical rolled structure (Figure 2). The elongated grains were formed in a pancake shape with their interfaces or grain boundaries parallel to the rolling plane and the BM was comprised of aluminum solid solution (white phase) and precipitates (black phase) dispersed in grain boundaries and grains.

\section{Mechanical properties}

Figure 8 is the hardness profile of the DWMW joint, and the white dotted line (Figure 5) represents the testing location. It should be noted that the WZ had a minimum hardness of only $\sim 90 \mathrm{HV}$ for the DWMW joint. Fracture generally occurred in the WZ adjacent to the FZ with a decrease in ductility, and there was no obvious necking around the facture (Figure 9). This behavior was consistent with the results of the microstructure analysis and hardness profile.

Static tensile nominal stress-strain curves of the weld joints are also examined to correlate the microstructural behavior (Figure 10). The mean ultimate tensile strength and elongation were $302 \mathrm{MPa}$ and $4.5 \%$, respectively.

The fracture surface exhibits no obvious porosity, slag inclusion and other defects (Figure 11(a)). As shown in Figures 11(b) and 11(c), fracture was consisted of equiaxed dimples of different sizes. The larger dimple size was about $15 \mu \mathrm{m}$ and the smaller was about $3 \mu \mathrm{m}$, showing a quasi-cleavage-like fracture characteristic. 

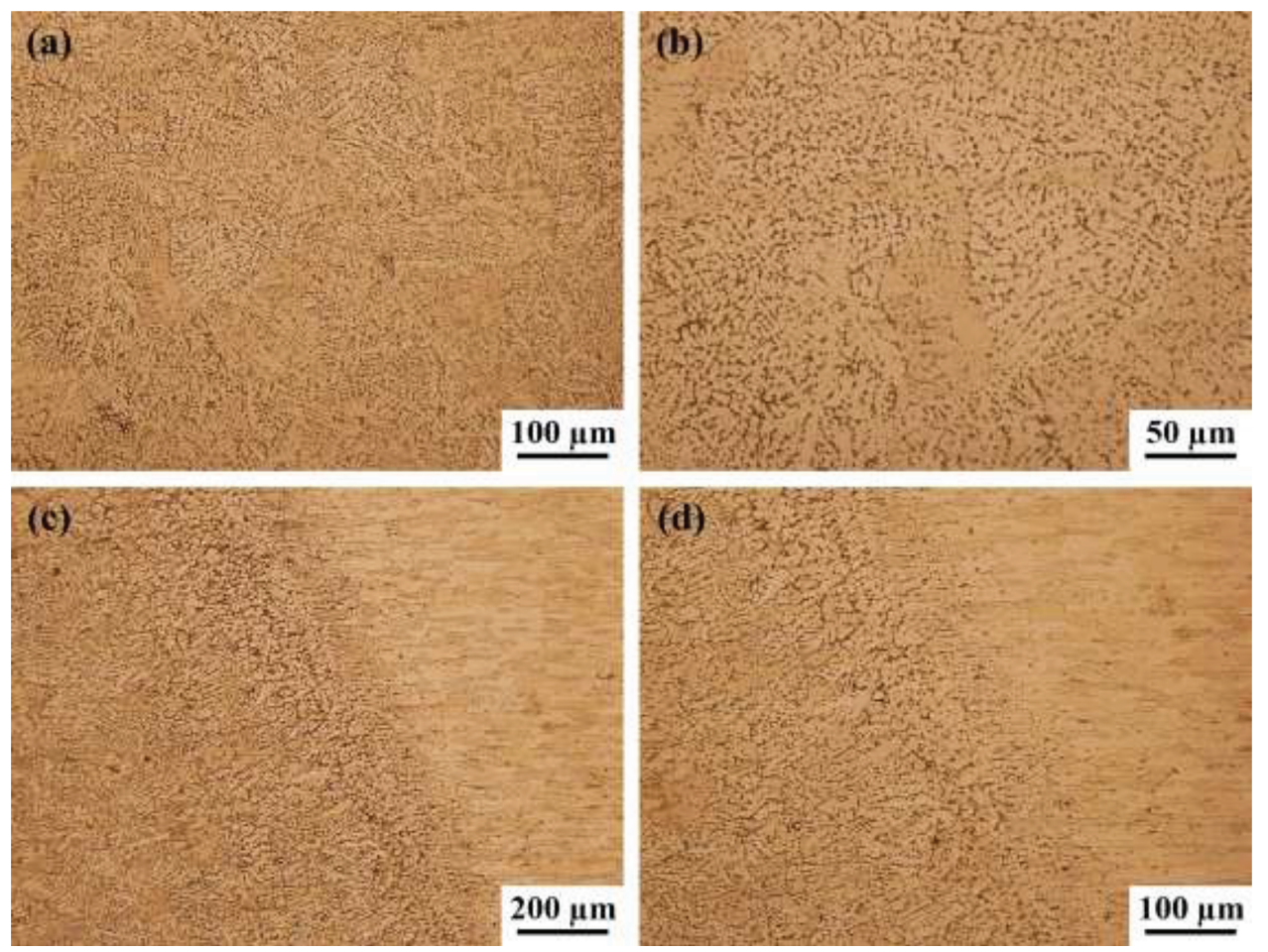

Figure 6: Micrographs of a DWMW A7N01P joint (1200 mm/min): (a) WZ and (b) its high magnification; (c) FZ and (d) its high magnification.

\section{Discussion}

\section{Microstructural evolution}

DWMW, at a high welding speed, experiences a rapid cooling process, so its solidification characteristics are a little different from that of the traditional MIG welding process.

Upon cooling, solidification of the FZ took place first at the partially melted or solid grains along the fusion boundary (i.e. at the solid-liquid interface), due to the cooling effect of the groove, the existence of large thermal gradient between the interface of BM and the molten pool, and small growth rate. In the subsequent solidification process, grains in the fine equiaxed crystal zone rapidly grew along to the preferred crystallographic directions. The proceeding would have the maximum growth speed toward the fusion center and subsequently grow into the columnar crystal structure (Figure 6(d)). This transition found near the FZ with coarser columnar grains had an abrupt change of grain size (Figure 6(d)), which maybe lead to a large gradient of mechanical properties.

The equiaxed dendritic grains in the $\mathrm{WZ}$ were formed (Figure 6(b)) due to the existence of dissociate dendrite arms and the mild cooling in the pool. The weld center was dominated by the heat sources and the strong arc stirring effect on weld pool. Because the T-arc had an additional stirring effect on the pool, it could break up the coarsened dendrite structure and offered lots of nucleation sites. This structure would benefit the mechanical properties of the DWMW bead.

The wide of the HAZ was a direct function of the heat input and thermal conductivity of the BM (Figure 6(c)). A larger grain size was attributed to the recrystallization effect and was very critical in the welding of aluminum alloys, especially which were hardened by precipitation.

\section{Welding efficiency analysis}

At present, due to competitive industrial market, the welding efficiency has become a matter of great concern [29-48], and the welding speed is one of the important factors to represent the welding efficiency.

Figure 12 shows the welding speeds of different fusion welding methods for $1-7 \mathrm{~mm}$ aluminum alloy plates $[1,5,8$, 13, 29-46]. As presented above, the welding speeds of MIG and tungsten inert gas (TIG) welding, below $1000 \mathrm{~mm} / \mathrm{min}$, were lower than that of other welding methods. Nevertheless, the above two welding methods have many 

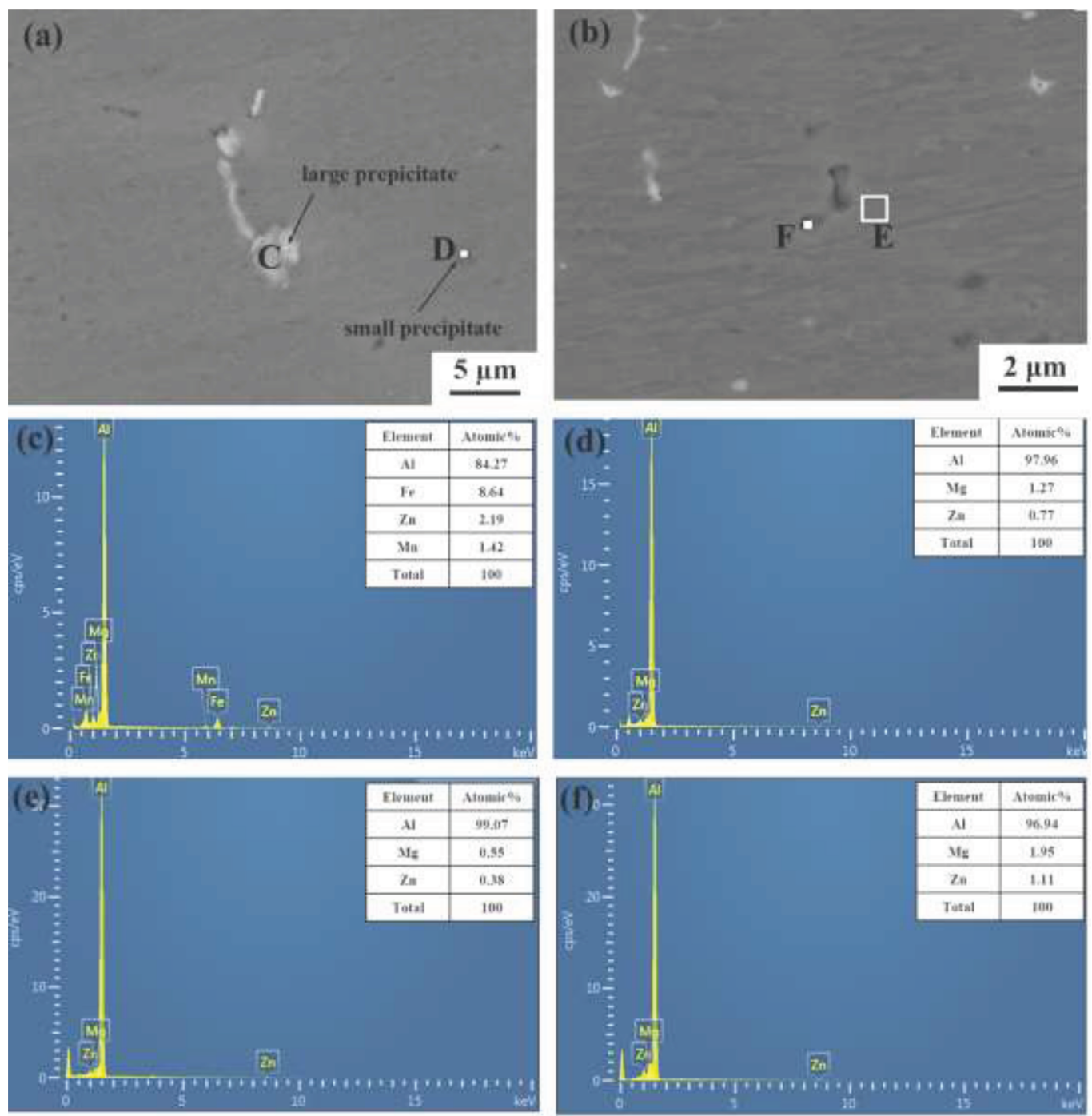

Figure 7: Images of SEM and EDS analysis: (a) detail of WZ in a DWMW joint; (b) typical EDS analysis of the large precipitate and (c) typical EDS analysis of the small percipitate.

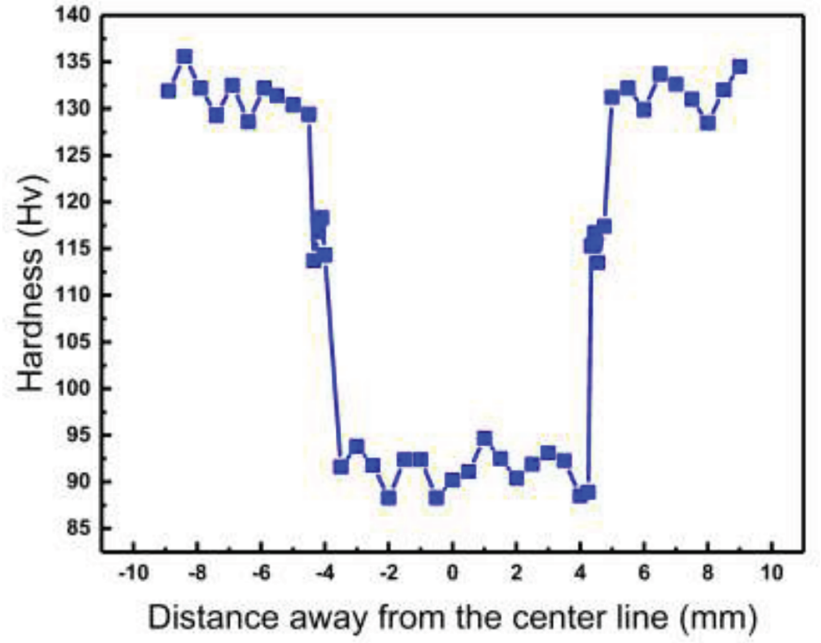

Figure 8: Hardness profile of the FZ and the HAZ of the DWMW joint. advantages such as simple operation, cheap equipment and cost reduction [7, 11]. In addition, laser welding and hybrid laser-arc welding could achieve a higher range of welding speeds from 1000 to $6000 \mathrm{~mm} / \mathrm{min}$. On the one hand, due to their high-energy density, they have a higher welding efficiency than that of arc welding. On the other hand, the equipment and welding costs are far higher, and they are susceptible to the occurrence of welding defects [8].

The red marks represent the welding speed interval produced by DWMW in this study. Compared to the traditional single-wire MIG welding, because two wires simultaneously provided heat energy to the BM, DWMW could change the heat distribution, effectively avoid undercut, yield welding seams with high quality, and improve the welding speed (1100-1200 mm/min) [26, 49]. In addition, in contrast to the traditional MIG and laser-arc welding 


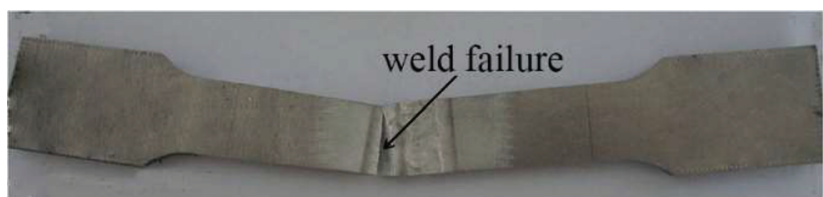

Figure 9: Global view of butt joint fractured.

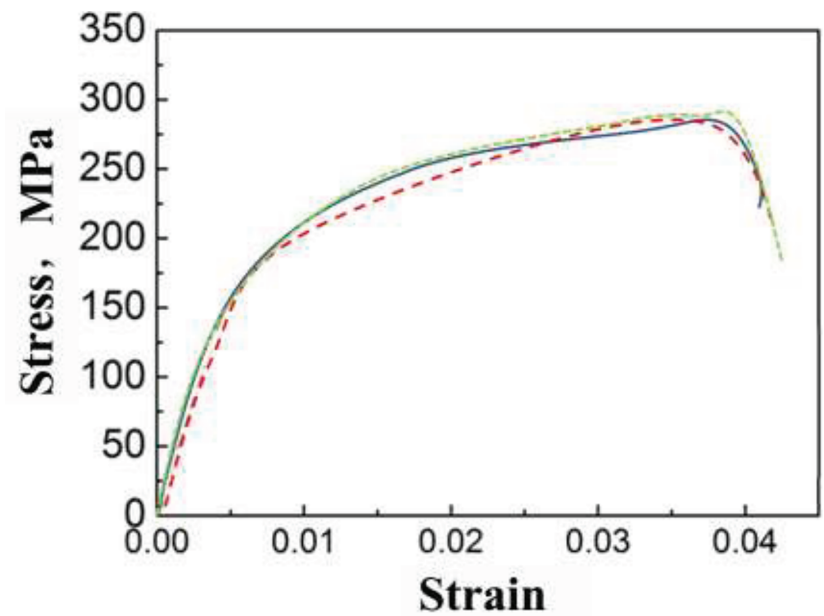

Figure 10: Nominal stress-strain curves of the DWMW joints.
$[7,50,51]$ which had a tensile strength between 260 and $341 \mathrm{MPa}$, DWMW improved the welding efficiency without reducing the mechanical properties of the joints, thereby having a wide application prospect in the field of aluminum alloy welding.

\section{Conclusions}

In summary, $4 \mathrm{~mm}$ thick A7N01-T4 aluminum alloy plates were welded by DWMW at a high welding speed of 1200 $\mathrm{mm} / \mathrm{min}$. For the DWMW joint of A7N01 aluminum alloy, the WZ showed a dendritic structure of equiaxed grains, and in the $\mathrm{FZ}$, the microstructure existed as a fine equiaxed crystal structure about $100 \mu \mathrm{m}$ in thickness. In the WZ adjacent to the FZ, elongated columnar crystal structure distributed along to the interface, and coarse microstructure in the HAZ were found showing a typical rolling texture. The main precipitates in the $\mathrm{WZ}$ were assumed to be Fe-enriched phases, and $\mathrm{Mg}$ - and $\mathrm{Zn}$-enriched phases. Tensile fracture generally occurred in the WZ adjacent to the FZ with a decrease in ductility, and it was consistent with the results of the microstructure analysis and
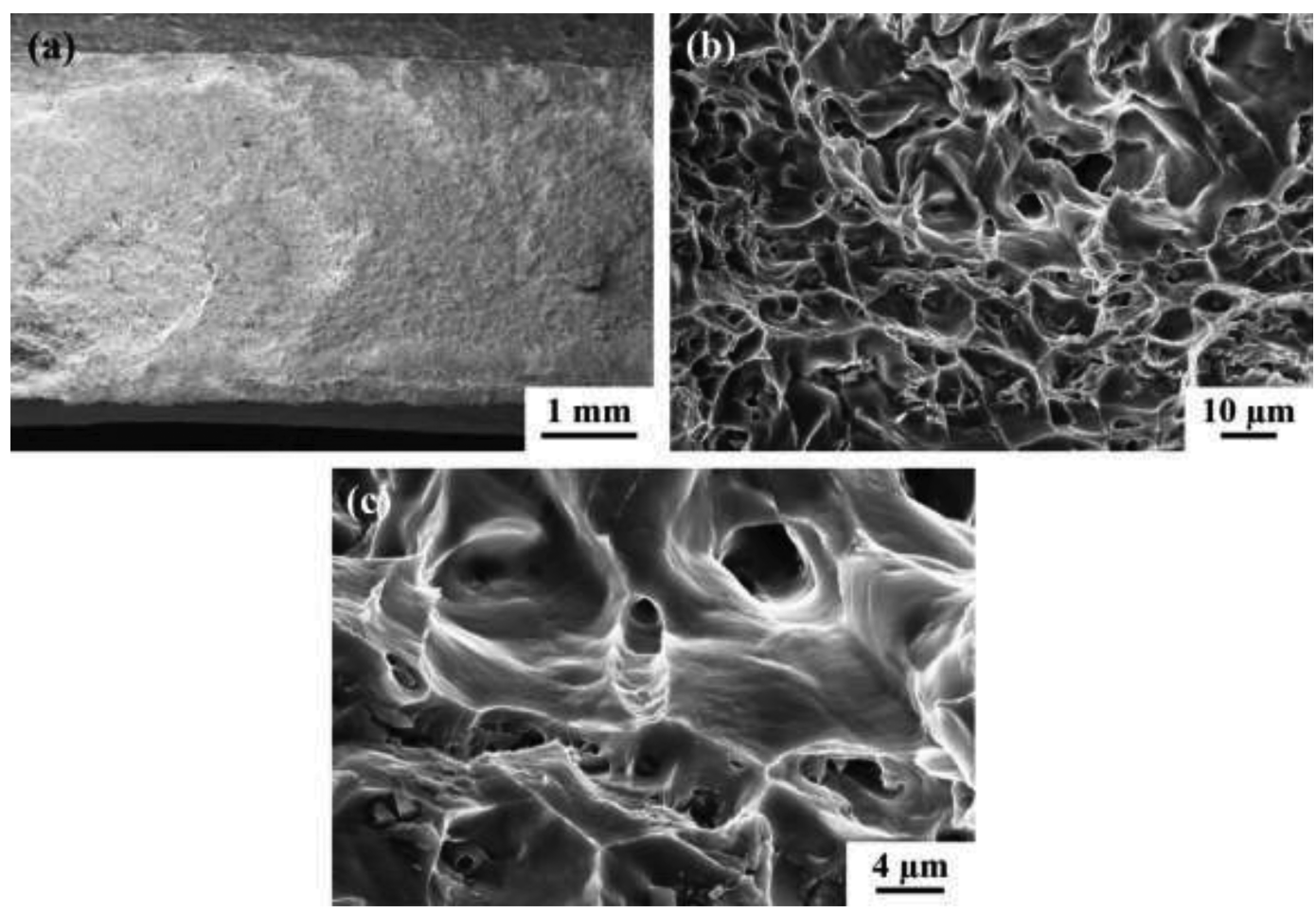

Figure 11: Fracture morphologies of a DWMW joint after tensile testing: (a) general view; (b) the ductile fracture appearance and (c) details of the ductile fracture surface. 


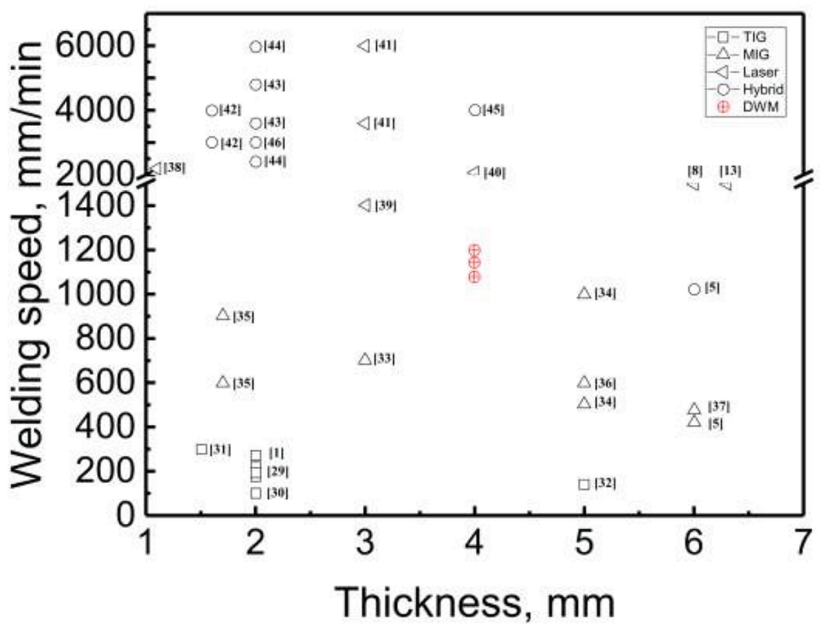

Figure 12: Comparison of welding speeds for aluminum alloys of varying thicknesses using different fusion welding methods $[1,5,8,13,29-46]$.

hardness profile. The mean ultimate tensile strength and elongation of specimens are $302 \mathrm{MPa}$ and $4.5 \%$, respectively. DWMW improved the welding efficiency without reducing the mechanical properties of the joints, thereby having a good application prospect.

Funding: This study was supported by the National Natural Science Foundation of China under Grant No. 51601121, and Liaoning Province Science Foundation Program No. L201624 and 201602570.

\section{References}

[1] L. Zhang, X.Y. Li, Z.R. Nie, H. Huang, J.T. Sun and J. Mater, Eng. Perform. , 25 (2016) 1870-1879.

[2] Q.J. Meng and G.S. Frankel, J. Electrochem. Soc., 151 (2004) B271-B283.

[3] S.S. Sharma, K. Jagannath and P.R. Prabhu, Int. J. Remote Sens., 29 (2013) 7003-7028.

[4] T.E. Borchers, D.P. Mcallister and W. Zhang, Metall. Mater. Trans. A, 46 (2015) 1827-1833.

[5] Q.Y. Wang, H. Chen, P.X. Qiu and Z.T. Zhu, Metall. Mater. Trans. B, 48 (2017) 1-11.

[6] S.D. Ji, X.C. Meng, J.W. Xing, L. Ma and S.S. Gao, High Temp. Mater. Proc., 35 (2016) 843-851.

[7] Z.C. Dai, X.W. Zhao, Z.H. Yun, J.J. Wu and Q.S. Li, Hot Work Technol., 44 (2015) 214-216.

[8] S. Katayama, A. Matsunawa and K. Kojima, Weld. Int., 12 (1998) 774-789.

[9] H. Zhao, D.R. White and T. DebRoy, Metallurgical Rev. , 44 (1999) 238-266.

[10] J.N. Qiao, J.X. Lu and S.K. Wu, Int. J. Fatigue , 98 (2017) 32-40.

[11] N. Xia, W.T. Jin, D.U. Gang, C.H. Zhou, G.E. Huai-Pu and G.Q. Gou, Electr. Weld. Mach., 44 (2014) 74-77.
[12] C. Liu, D.O. Northwood and S.D. Bhole, Mater. Des. , 25 (2004) 573-577.

[13] O.T. Ola and F.E. Doern, Mater. Des. , 77 (2015) 50-58.

[14] S.L. Yang, B. Luo, R.Y. Lv, L.C. Meng and Q.L. Lin, Adv. Mater. Res., 430-432 (2012) 2091-2094.

[15] N.B. Potluri, P.K. Ghosh, P.C. Gupta and Y.S. Reddy, Weld. J., 75 (1996) 660-666.

[16] S.D. Ji, Z.W. Li, Y. Wang, L. Ma and L.G. Zhang, High Temp. Mater. Proc., 36 (2016) 693-699.

[17] A.G. Paleocrassas and J.F. Tu, Feasibility investigation of laser welding aluminum alloy 7075-T6 through the use of a $300 \mathrm{~W}$, single-mode, ytterbium fiber optic laser, North Carolina State University, America (2005).

[18] S. Katayama and K. Ogawa, Weld. Int., 27 (2013) 172-183.

[19] B. Hu and I.M. Richardson, Weld. World, 50 (2013) 51-57.

[20] G. Campana, A. Ascari, A. Fortunato and G. Tani, Appl. Surf. Sci., 255 (2009) 5588-5590.

[21] S. Liu, J. Li, G. Mi, C. Wang and X. Hu, Int. J. Adv. Manuf. Technol., 87 (2016) 1-10.

[22] X.L. He, C. Cao, P. Qiu and Y. Cui, Electr. Weld. Mach., 45 (2015) 32-35.

[23] D.J. Ye, X.M. Hua, C. Xu, F. Li and Y.X. Wu, Int. J. Adv. Manuf. Technol., 89 (1-4) (2016) 1-10.

[24] J. Zhu, Y. Wang, D. Chen, Z. Ming, B. Tan and H. Liu, Ordnance Mater. Sci. Eng. , 32 (2009) 39-42.

[25] H. Miyazaki, H. Miyauchi, Y. Sugiyama and T. Shinoda, Weld. Int., 7 (1993) 431-437.

[26] P. Yao, J.X. Xue, K. Zhou, X.J. Wang and Q. Zhu, J. Mater. Process. Technol., 229 (2016) 111-120.

[27] P. Yao, J.X. Xue and K. Zhou, Int. J. Adv. Manuf. Technol., 79 (2015) 2107-2116.

[28] P. Yao, J.X. Xue, K. Zhou and X.J. Wang, Math. Probl. Eng., 10 (2014) 1-8.

[29] J. Shi, H.U. Ming-Hua, X.Q. Zhu and W.J. Chen, Electr. Weld. Mach., 44 (2014) 146-148.

[30] Y.Q. Zhang, C.L. Yang, S.B. Lin and C.L. Fan, Trans. China Weld. Inst., 36 (2015) 53-56.

[31] D.X. Yang, X.Y. Li, Z.R. Nie, D.Y. He, H. Huang and G.Z. Zhang, Rare Metal Mater. Eng., 41 (2012) 1713-1716.

[32] K. Yan, Z.Q. Shi and X.L. Wang, Trans. China Weld. Inst., 33 (2012) 33-36.

[33] P.M.G.P. Moreira, M.A.V.D. Figueiredo and P.M.S.T.D. Castro, Theor. Appl. Fract. Mec., 48 (2007) 169-177.

[34] Y.P. Kim, N. Alam, H.S. Bang and H.S. Bang, Sci. Technol. Weld. Joining, 11 (2006) 295-307.

[35] Z.D. Zhang and X.Y. Kong, Adv. Mater. Res., 295-297 (2011) 1933-1937.

[36] P. Kah, M. Olabode, E. Hiltunen and J. Martikainen, Mechanika, 19 (2013) 96-103.

[37] N. Xia, W.T. Jin, G. Du, C.H. Zhou and H.P. Ge, Electr. Weld. Mach., 44 (2014) 74-77.

[38] H.H. Yan, K.F. Zhang and Y. Wu, Trans. China Weld. Inst., 32 (2011) 97-100.

[39] L. Cretteur and S. Marya, Weld. Int., 14 (2000) 120-134.

[40] R. Akhter, L. Ivanchev and H.P. Burger, Mater. Sci. Eng. A, 447 (2007) 192-196.

[41] A. Ancona, P.M. Lugarà, D. Sorgente and L. Tricarico, J. Mater. Process. Technol., 191 (2007) 381-384.

[42] R. Braun, Mater. Sci. Eng. A, 426 (2006) 250-262. 
[43] D.Q. Zhang, X. Jin, L.X. Gao, H.G. Joo and K.Y. Lee, Mater. Sci. Eng. A, 528 (2011) 2748-2754.

[44] B. Hu and I.M. Richardson, Mater. Sci. Eng. A, 459 (2007) 94-100.

[45] J.N. Qiao, Q.M. Wang, J.L. Zou and S.K. Wu, China J. Lasers, 43 (2016) 62-69.

[46] S.C. Wu, X.B. Xu, W.H. Zhang, Z. Li and D.R. Xu, Trans. China Weld. Inst., 33 (2012) 45-48.

[47] S.D. Ji, Y. Wang, Z.W. Li, L. Ma, L.G. Zhang, Y.M. Yue and H. Temp, Mater. Proc., 36 (2017) 693-699.
[48] K. Laha, K.S. Chandravathi, K.B.S. Rao, S.L. Mannan and D.H. Sastry, High Temp. Mater. Proc., 19 (2000) 141-150.

[49] K. Li and Y.M. Zhang, IEEE Trans. Autom. Sci. Eng., 7 (2010) 826-839.

[50] X.Y. Yang, H. Chen, Q.Y. Wang and Z.T. Zhu, Trans. China Weld. Inst., 37 (2016) 114-118.

[51] G.X. Chen, Study on mechanical properties and stress corrosion behavior of A7N1S-T5 aluminum alloy MIG welded joints, Qingdao University of Science \& Technology, Master Dissertation, (2015). 